\title{
Laicidad liberal y laicismo
}

\section{Liberal Laicité and Laicism}

\begin{abstract}
Alfonso Ruiz Miguel
Autor:

Alfonso Ruiz Miguel

Universidad Autónoma de Madrid, Espańa

alfonso.ruiz@uam.es

Recibido: $11-8-2020$

Aceptado: 15-11-2020

Citar como:

Ruiz Miguel, Alfonso, (2021). Laicidad liberal y laicismo Doxa. Cuadernos de Filosofía del Derecho, 44, pp. 475-482. https://doi.org/10.14198/ DOXA2021.44.18

Licencia:

Este trabajo se publica bajo una Licencia Creative Commons Atribución 4.0 Internacional.

\section{Resumen}

El texto prosigue un debate oral con Manuel Atienza recuperado en su prólogo a un reciente libro de Giovanni Blando. En este libro se recoge mi tesis, contra la que reacciona Atienza, de que la laicidad apropiada en un Estado aconfesional es una laicidad liberal o neutral, situada entre dos extremos: la llamada laicidad positiva, que es una forma de confesionalidad encubierta, y el laicismo, entendido como una forma de laicidad no liberal y no neutral hacia las religiones. El debate gira sobre todo en torno a esta última categoría.
\end{abstract}

\section{(c) (i)}

(C) Alfonso Ruiz Miguel
Palabras clave: Laicidad; laicismo; laicidad positiva; libertad religiosa; neutralidad; liberalismo.

\begin{abstract}
The text continues an oral debate with Manuel Atienza retrieved in his preface to a recent book of Giovanni Blando. This book endorses my thesis, against which Atienza reacts, that the proper form of laicite in a non-confessional State is a liberal or neutral laicitè, which should be placed between two opposite extremes: the so called positive laicité, actually a form of undercover confessionality, and laicism, understood as a form of non liberal laicité, non neutral towards religion. The debate mainly gravitates around this last cathegory.
\end{abstract}

Keywords: laicitè; laicism; positive laicité; religious freedom; neutrality; liberalism. 


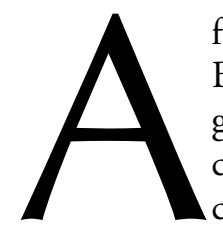

finales del pasado año se publicó en Italia un estimable libro de Giovanni Blando sobre la laicidad (BLANDo 2019). Su origen es una tesis doctoral gestada en Alicante y leída en febrero de ese mismo año en Nápoles en cuyo acto de lectura, entre diversos acuerdos, Manuel Atienza y yo intercambiamos una más añeja discrepancia que él vuelve a desarrollar en el prólogo al libro (ATIENZa 2019: 19-22). El debate versa sobre una distinción que estos pasados años he utilizado para construir una visión de la laicidad estatal correcta, la única que considero genuina y defendible, como una posición intermedia entre la denominada "laicidad positiva», que es en realidad una forma de confesionalidad encubierta que favorece a las religiones (sea a una o varias en particular o a todas en general), y lo que he venido denominando laicidad radical o militante, o también laicismo, que adopta una posición beligerante contra las creencias religiosas en cuanto tales, sea en general o en alguna de sus manifestaciones. Caractericé a aquella posición intermedia como liberal o neutral para defenderla como la laicidad que debe proteger un Estado comprometido con el respeto a una igual libertad religiosa ${ }^{1}$. La triple distinción anterior, junto con la defensa de la laicidad neutral, fue acogida en su tesis y en su libro por Giovanni Blando, que además recientemente ha dedicado un artículo a la crítica del más bien insidioso concepto de laicidad positiva (Blando 2021). No me parece que ni Atienza ni yo mismo tengamos discrepancias sobre este último concepto, pero puede ser de interés abrir un pequeño debate en Doxa sobre el otro cabo de la tríada, la laicidad radical, según acordamos a sugerencia del propio Blando.

Atienza, en efecto, no tiene especiales objeciones al uso crítico que tanto Blando como yo hemos hecho de la categoría de la laicidad positiva, que, tras siglos de franca negación de la libertad religiosa bajo el lema «no hay libertad para el error», el pensamiento católico oficial relativamente reciente viene considerando como la única «sana laicidad» en contraposición al denostado «laicismo» (cf. BLANDo 2021: 1-3). La posición católica es claramente dicotómica, hasta el punto de que el Papa Bergoglio ha terminado por proponer sin más la «diferencia entre laicismo y laicidad» para condenar al primero porque "cierra las puertas a la trascendencia", en contraposición a la «sana laicidad, por ejemplo, la laicidad del Estado», preferible a la confesionalidad, «porque los Estados confesionales terminan mal»". Parece que Atienza comparte esta misma visión dicotómica, solo que invirtiendo el sentido y la valoración de cada uno de los dos términos: mientras la laicidad positiva sería, como para Blando o para mí, una forma insuficiente, falsa o "patológica» de laicidad, en cambio, el laicismo sería su única forma apropiada. Lo que en la crítica de Atienza queda igualmente excluido es el tertium defendido por Blando y por mí de una virtuosa vía intermedia entre los

1. Vengo ocupándome con cierta asiduidad del tema de la laicidad desde 2007, así que, como en este escrito estoy condenado a repetirme, trataré de hacerlo sin copia y pega alguno, de modo que las mismas ideas se presenten en forma diferente. Los principales de esos textos se citan en la bibliografía.

2. "Intervista del Santo Padre Francesco al settimanale cattolico belga "Tertio", 07.12.2016», en https://press. vatican.va/content/salastampa/it/bollettino/pubblico/2016/12/07/0882/01951.html\#ita (se cita por el texto original en español). 
dos extremos patológicos de la laicidad positiva y del laicismo, entendido este siempre como laicidad radical o no neutral por parte del Estado.

Los argumentos de Atienza para adoptar un modelo dicotómico frente a la tríada por mí propuesta y asumida por Blando son básicamente dos. El primero es que nuestra caracterización crítica de la laicidad radical o laicismo tiene, dice, «mucho de artificioso", queriendo decir que es un concepto que distorsiona el verdadero significado de la laicidad genuina, que, por implicación, para Atienza no se distinguiría del laicismo. Tal me parece el sentido de las dos objeciones a nuestra caracterización (en realidad, a la de Blando, tal y como aparece en su libro) con las que desarrolla este primer argumento: (a) que ni las constituciones ni los autores partidarios de la laicidad radical quedan identificados, implicando presumiblemente que porque no existen (Atienza aventura que quizá queremos aludir al "caso francés», pero replica con el inconcluyente argumento, que enseguida comentaré, de que le «resulta muy difícil aceptar que la Constitución francesa sea contraria a la igualdad, a la neutralidad y a la tolerancia en materia religiosa»); y (b) que la distinción entre laicidad positiva y laicidad radical está «viciada [...] por una cierta deformación ideológica», tanto porque por el lado de la primera olvidaría el «dato histórico fundamental» de que la Iglesia católica ha obstaculizado ideológicamente la difusión del Estado constitucional y aconfesional, como porque por el lado del laicismo la específica acusación de Giovanni Blando contra él de ser intolerante olvidaría erróneamente la eventual simetría patológica con la laicidad positiva, que, ella sí, es claramente intolerante en cuanto defiende públicamente la superioridad de la religión sobre el agnosticismo o el ateísmo (cf. AtIENZA 2019: 21-22).

El segundo argumento de Atienza es que la posición neutral entre las dos anteriores defendida por Blando y por mí, que yo he caracterizado como "meta-agnóstica", no resultaría posible, dando lugar a una propuesta poco convincente por utilizar una categoría inexistente e imposible de defender. En este punto, Atienza recoge la formulación de tal meta-agnosticismo que aparece en el libro de Giovanni Blando, como abstención por parte del Estado «de cualquier valoración, incluso meramente dubitativa, en materia de concepciones éticas" (BLANDo 2019: 143), para contraargumentar que cualquier constitución presupone necesariamente la adopción de alguna concepción ética y que ciertos valores constitucionales justificables son incompatibles con los de algunas religiones. Enseguida añade que incluso puede haber una incompatibilidad en la fundamentación última entre dichos valores y quizá todas las religiones, si estas suponen un absolutismo moral inmune a la crítica, a diferencia del objetivismo moral mínimo típico de los sistemas democrático-constitucionales (ATIENZa 2019: 22).

Las dos anteriores razones apuntan a blancos diferentes: mientras la primera, de validación más empírica, tiende a impugnar la oportunidad de nuestra conceptualización negando la utilidad de la categoría de la laicidad radical, que según Atienza no correspondería a posiciones jurídicas o teóricas realmente existentes, en cambio, la segunda, de carácter más conceptual, apunta a la imposibilidad lógica de la categoría misma, de manera que entre confesionalidad (incluyendo en ella la laicidad positiva) y laicidad o laicismo tertium non datur. Creo que ninguna de las dos críticas da en el 
blanco, y mostrarlo con detalle permitirá descubrir también algún malentendido en la argumentación de Atienza debido a una lectura errónea de una de mis tesis por parte de Blando. Vayamos por partes, salvo que diga otra cosa haciendo referencia sobre todo a lo que yo he podido defender en mis escritos sobre el tema.

Comenzando por el primer argumento de Atienza, la clasificación tricotómica entre laicidad radical-laicidad positiva-laicidad neutral no es más que una tipología ideal que pretende dar cuenta de un continuo gradual de posiciones reales diferentes. Como el conjunto de casos posibles es graduable y la clasificación es triádica, cada uno de los tres conceptos fija los rasgos distintivos que caracterizan los casos más claros del continuo, respectivamente los situados más cerca de los dos extremos y alrededor del punto medio o central. La utilización de los tres conceptos no pretende negar que en la realidad pueda haber zonas de transición en las que no se pueda aplicar a la perfección uno solo de los conceptos, sino solo destacar de forma nítida los tres tipos ideales, de los cuales uno de ellos, el de la laicidad neutral, se presenta como valorativamente preferible en contraste con los otros dos a sus extremos. Si me he aprovechado con acierto o con alevosía de la estrategia del in medio virtus dependerá solo, como en el caso de las descripciones aristotélicas de unas u otras virtudes, de que las categorías elegidas estén razonablemente bien construidas y sean valorativamente aceptables para reflejar una graduación de posiciones relevante en la realidad.

En mi propuesta, los extremos de la laicidad positiva y la laicidad militante o laicismo, siempre entendidos como posición del Estado, son conceptualmente simétricos y valorativamente nocivos para la igualdad y la libertad en materia religiosa (digo entre paréntesis que tiendo a utilizar la expresión «libertad en materia religiosa» mejor que la de «libertad religiosa» para marcar que esta libertad abarca no solo la profesión de cualesquiera creencias religiosas en el sentido convencional de la expresión, sino también la de cualquier creencia sobre la religión, incluidas las ideas antirreligiosas, así como la licitud de adoptar, cambiar o renunciar a unas y a otras). La laicidad positiva es nociva porque favorece las creencias religiosas discriminando a las ateas y agnósticas, y el laicismo porque hace precisamente lo opuesto. En medio de ambas, la laicidad neutral pretende tratar por igual la posibilidad de que los individuos ejerzan libremente sus creencias en materia religiosa, sean favorables, desfavorables o indiferentes a estos o aquellos dioses, a la trascendencia del alma o al sentido de la vida, de la historia o del universo (siempre, claro está, con el límite de no afectar a derechos básicos ajenos).

La aplicabilidad de la categoría del laicismo a la realidad, sea en este caso jurídica o ideológica, me parece fácil de ejemplificar de manera bastante pura en el ateísmo de Estado (o del partido único) practicado en la China maoísta o en la Unión Soviética ${ }^{3}$, y de manera más moderada, con elementos mixtos de laicidad neutral y radical, en el

3. Sobre ello remito a Baubérot 2010: 69 y 83; Goossaert 2005: 54; y Boyкo 2005: 260ss.

Como Atienza también pide autores defensores del laicismo, citaré a Larry AleXANDER (1993), que impugnando la distinción rawlsiana a la que luego me referiré entre concepciones de lo bueno y criterios de justicia, intenta probar que el liberalismo en una concepción moralmente verdadera que permite ser intolerante con las falsas creencias religiosas que se le oponen. 
régimen constitucional mexicano y en la práctica legislativa francesa. En el caso mexicano, existen normas laicistas a mi modo de ver difícilmente justificables, como las que excluyen los derechos de sufragio pasivo, asociación política y libertad de expresión a los ministros de los cultos y a las organizaciones religiosas, que conviven con un diseño constitucional de separación Estado-iglesias irreprochable en general que incluye normas de laicidad neutral perfectamente imparciales y defendibles, como las que impiden, incluso de manera muy rigurosa, la utilización de motivos religiosos por los partidos políticos en la denominación o la propaganda electoral ${ }^{4}$. En el caso francés, que en general puede considerarse como un aceptable modelo de laicidad neutral, existen algunas regulaciones y prácticas, entre ellas precisamente las que prohíben al alumnado cualquier uso de ropas o símbolos religiosos en el ámbito escolar, que incurren en una criticable posición laicista y vienen a negar los valores constitucionales de igualdad y tolerancia en materia religiosa ${ }^{5}$. Que tales casos sean toscos manchones o, como dice Atienza, "pequeños matices» que deslucen el carácter liberal del sistema francés en conjunto, nada de ello desmiente el valor de la categoría del laicismo para interpretar y criticar tales excesos, precisamente por su contraste con el modelo de la laicidad neutral.

Antes de pasar a comentar el segundo argumento de Atienza me parece importante precisar, como ya he hecho en varios escritos, que, mi posición se diferencia de la valoración habitual de la Iglesia católica contra el laicismo, que no solo condena indistintamente la laicidad radical y la neutral en cuanto ninguna de las dos asume un trato preferente a la religión, sino que tampoco discrimina entre el plano público y el privado. Desde mi punto de vista, el laicismo es condenable única y exclusivamente como actitud estatal ante las religiones, pero no en absoluto como actitud de los individuos, cuyo derecho a creer o no creer y a expresar y defender cualquier creencia en materia religiosa debe entenderse como una manifestación valiosa de la libertad que precisamente un Estado comprometido con la laicidad neutral está llamado a respetar y garantizar en condiciones de igualdad. Por esa razón, mientras el Estado está obligado a ser tolerante en materia de religión bajo la actitud meta-agnóstica mencionada, los individuos no tienen por qué ser tolerantes en el mismo sentido, pudiendo ejercer libremente su derecho tanto a auspiciar e intentar propagar sus propias creencias como a criticar militantemente las ajenas. La independencia conceptual entre el laicismo como creencia particular y la laicidad del Estado como criterio ético público resulta clara en cuanto se cae en la cuenta de que tal criterio público, si como creo está justificado por

4. Con más detalles, recogí el tema en un debate con Rodolfo Vázquez (cf. Ruiz Miguel 2010: 81-86; cf. también Ruiz Miguel 2020: 182-184 y nota 9, con la bibliografía allí citada).

Por cierto, añado ahora en relación con el último tipo de regulaciones que menciono en el texto, las cuales en la mayoría de los países europeos de Europa son inexistentes o tolerantes (baste citar a los partidos democristianos), que el artículo 47.3 de la Constitución portuguesa establece la siguiente limitación: «Los partidos políticos no podrán, sin perjuicio de la filosofía o ideología que inspire su programa, utilizar denominación que contenga expresiones directamente relacionadas con religión o iglesia alguna, así como emblemas confundibles con símbolos nacionales o religiosos».

5. Para más detalles y matices, cf. Ruiz Miguel 2012: $\$$ II.3, así como Ruiz Miguel y Villavicencio 2014: 104-106. 
respeto a la igual libertad de los individuos, debería ser aceptado idealmente por todos, sean laicistas, agnósticos o creyentes de cualquier confesión (para un mayor desarrollo, Ruiz Miguel 2020: 183-184).

El segundo argumento de Manuel Atienza, que la neutralidad es imposible en esta materia, contiene un malentendido sobre la categoría del meta-agnosticismo. Como he dicho, Atienza toma la caracterización que de este término propone Blando en su libro, como abstención por parte del Estado «de cualquier valoración, incluso meramente dubitativa, en materia de concepciones éticas». Así formulado, Atienza tiene razón en que el meta-agnosticismo estatal es imposible porque, en efecto, ni el Estado democráticoliberal más neutral puede dejar de presuponer y aplicar valoraciones éticas, incluso coactivamente, como mínimo en la esfera de la protección de los derechos: sin ir más lejos, el código penal trata de evitar mediante sanciones coactivas las conductas lesivas de derechos porque el Estado está no solo justificado sino incluso obligado éticamente a proteger a los individuos.

Sin embargo, en mis escritos sobre el tema, incluido el que Blando cita en ese punto, nunca he sostenido que el meta-agnosticismo estatal deba ni pueda practicarse respecto de las concepciones éticas, sino en exclusiva de las concepciones religiosas, y, para ser más preciso, de las concepciones en materia religiosa, es decir, sean positivamente religiosas, indiferentes o contrarias a las religiones en el sentido más común de la palabra ${ }^{6}$. Con esa delimitación quiero adelantarme a la posible réplica de que existen religiones cuyas prescripciones éticas son de naturaleza idiosincrásica, de manera que en ellas resulta indistinguible el criterio ético de la fundamentación religiosa misma. En tales casos, si existe grave conflicto, es claro que la neutralidad estatal resulta imposible (y si fuera posible, resultaría indeseable), como también es imposible e indeseable que el Estado sea neutral entre ciencia y religión cuando las creencias religiosas pretenden adentrarse en la esfera de los conocimientos sometidos a criterios de validación científica: sería absurdo que el Estado financiara equitativamente las investigaciones que requieren grandes aceleradores de partículas y los estudios de demonología.

Ciertamente, existen algunas diferencias importantes entre la ciencia y la ética en sus posibles relaciones con las religiones, pero el punto relevante en lo que se refiere a la actitud del Estado sobre esas relaciones descansa, en mi opinión, sobre un criterio ético que justifica la delimitación de la esfera de actuación de las creencias religiosas dentro del estricto ámbito de sus creyentes. Como lo he formulado con mayor detalle en dos escritos sobre el tema, por razones de respeto a la autonomía individual las creencias

6. Como digo en el texto al que remite Blando (2019: 143), la posición meta-agnóstica «adoptaría la actitud previa de quien no sólo se niega a afirmar nada positivo en materia religiosa, ni siquiera la mera duda, sino que incluso se niega a entrar en la consideración de si debe dudarse sobre ello" (Ruiz Miguel y Villavicencio 2014: 104; cursiva mía; donde reproduzco un paso de Ruiz Miguel 2013: 26); o como repito en mi último escrito sobre el tema, «el Estado verdaderamente laico debe ser meta-agnóstico, esto es, debe ser ajeno a cualquier pregunta y respuesta relativa a la religión. O, dicho de otra manera, el Estado no puede ni debe solo limitarse a dudar, como puede hacer el individuo agnóstico, sino que asume el deber de no pronunciarse sobre la materia religiosa, ni siquiera para afirmar que duda» (Ruiz Miguel 2020: 185). 
idiosincrásicamente religiosas solo pueden ser válidas para quienes las profesan, sin que puedan imponerse mediante la fuerza del Derecho en la esfera pública a quienes no las comparten ${ }^{7}$.

Frente a la anterior argumentación alguien, aunque no creo en absoluto que Atienza, podría desear asimilar criterios éticos y religiosos por la vía de destacar las reconocibles diferencias entre el tipo de objetividad de la ciencia y el de la ética, este segundo sujeto a criterios ajenos a la validación empírica y en todo caso carentes de convenciones compartidas como las propias del consenso de los científicos. Esta réplica podría continuar reproduciendo los conocidos argumentos sobre la imposibilidad de neutralidad de los principios liberales, que no dejarían de ser una posición ética parcial culturalmente situada tan subjetiva y discutible como las posiciones éticas idiosincrásicamente religiosas. Frente a esta debatible identificación entre ética y religión, en estas rápidas notas solo cabe «recurrir» al principio liberal, seguro que compartido con Manuel Atienza y Giovanni Blando, que diferencia entre concepciones de lo bueno y concepciones de lo correcto o justo para insistir en que los criterios éticos adoptados y utilizados por un Estado democrático-liberal pueden ser suficientemente neutrales si se circunscriben a la esfera del consenso por superposición teorizada por Rawls (1987; y 2005: IV-V). Y por definición, en ese consenso, no pueden entrar ni las razones idiosincrásicamente religiosas ni las que, con algún paralelismo con ellas, se puedan alegar en favor del ateísmo, el agnosticismo o cualquier posición en materia religiosa.

Releídas las páginas anteriores, me queda el regusto áspero de haber destacado sobre todo un punto de desacuerdo con el amigo Manuel Atienza cuando desde una visión más distanciada lo que domina es más bien la amplitud de nuestros acuerdos. En todo caso, tengo una firme confianza en que mis razones, junto a las que él y Giovanni Blando puedan añadir a este debate, servirán para un mejor entendimiento, entre nosotros y entre los lectores, del eterno reto que las creencias y las actitudes en materia religiosa plantean en la esfera pública.

\section{BIBLIOGRAFÍA}

Alexander, L. 1993: "Liberalism, Religión, and the Unity of Epistemology», San Diego Law Review, 30: 763-797.

Atienza, M., 2019: «Prólogo» a Blando 2019: 13-23.

Baubérot, J. 2010: Les läcités dans le monde, 4a ed., París, Presses Universitaires de France.

Baubérot, J., y Wieviorka, M., 2005: De la séparation des Églises et de l'État à l'avenir de la laïcité (Les Entretiens d'Auxerre 2004), La Tour d'Aigues, Éditions de l'Aube.

Вочко, N., 2005: «Présent et devenir de la laïcité en espace postsovietique (Ukranie, Russie, Bélarus)», en BAUBÉrot y Wieviorka 2005.

7. Cf. Ruiz Miguel 2010: 59-69; así como, con precisiones importantes sobre el anterior, Ruiz Miguel 2018: 413-423). 
Blando, G., 2019: Secularizzazione e laicitá. Practiche argomentative nella CEDU, prólogo de Manuel Atienza, Nápoles, Editoriale Scientifica.

BlANDO, G., 2021: «La laicità positiva come negazione della laicità» (pendiente de publicación).

Goossaert, V., 2005: «Les fausses séparations de l'État et de la religión en Chine, 18982004», en Baubérot y Wieviorka 2005.

Rawls, J., 1987: "The Idea of an Overlapping Consensus», Oxford Journal of Legal Studies, 7(1): 1-25; trad. de J. C. Bayón, «La idea de un consenso por superposición, en J. Betegón y J. R. de Páramo (eds.), Derecho y moral. Ensayos analiticos, Barcelona, Ariel, 1990: 63-86.

Rawls, J., 2005: Political Liberalism. Expanded Edition, Nueva York, Columbia University Press, 2005 (hay trad. de A. Domènech de la $1^{\text {a }}$ ed. de 1993, El liberalismo político, Barcelona, Crítica, 1996).

Ruiz Miguel, A., 2007: "Laicidad, laicismo, relativismo y democracia», Sistema. Revista de Ciencias Sociales, 199: 3960.

Ruiz Miguel, A., 2009: «Para una interpretación laica de la Constitución», en A. Ruiz Miguel y R. Navarro-Valls, Laicismo y Constitución, 2a ed., Madrid, Fundación Coloquio Jurídico Europeo: 31-95.

Ruiz Miguel, A., 2010: «La laicidad y el eterno retorno de la religión», en R. Vázquez, A. Ruiz Miguel y J. M. Vilajosana, Democracia, religión y Constitución, Madrid, Fundación Coloquio Jurídico Europeo: 47-89.

Ruiz Miguel, A., 2012a: "Libertad religiosa, símbolos religiosos y laicidad estatal», en I. Gutiérrez y M. Á. Presno (eds.), La inclusión de los otros: símbolos y espacios de la multiculturalidad, Granada, Editorial Comares: 6997.

Ruiz Miguel, A., 2012b: «Para una crítica de la laicidad positiva», Jueces para la Democracia. Información y Debate, 75: 3448.

Ruiz Miguel, A., 2013: Laicidad y constitución, México, Universidad Nacional Autónoma de México, 2013 (puede verse en edición electrónica en http://biblio.juridicas.unam.mx/ libros/libro.htm?l=3241).

Ruiz Miguel, A., 2018: "Razón pública, tolerancia e idiosincrasia religiosa», en J. Cerdio, P. Larrañaga y P. Salazar (coords.), Entre la libertad y la igualdad. Ensayos críticos sobre la obra de Rodolfo Vázquez, México, UNAM-Instituto de Investigaciones Jurídicas, tomo II, pp. 413-423 (también en https://goo.gl/pZiZhn).

Ruiz Miguel, A., 2020: «Laicidad y libertad religiosa», en A. Ruiz Miguel, Cuestiones de principios: entre politica y Derecho, Madrid, Centro de Estudios Políticos y Constitucionales: cap. 6.

Ruiz Miguel, A., y Villavicencio Miranda, L. 2014: «Estado y religión. Una justificación liberal de la laicidad neutral», Revista Española de Derecho Constitucional, 102: 93-126. 